\title{
LA PONENCIA COLECTIVA (1937) DE ARTURO SERRANO PLAJA: UNA TOMA DE POSICIÓN LITERARIA Y POLÍTICA EN LA GUERRA CIVIL
}

\author{
Klaus Meyer-Minnemann, AnA Luengo, \\ DANIELA PÉREZ Y EFFINGER \\ Universidad de Hamburgo
}

La Ponencia Colectiva leída el 10 de julio de 1937 por Arturo Serrano Plaja se considera uno de los más importantes discursos pronunciados en el Segundo Congreso Internacional de Escritores para la Defensa de la Cultura que, entre el 4 y 17 de julio de aquel año, se celebró en Valencia, Madrid, Barcelona y París. Schneider $(1987,157)$ observa que la Ponencia «si no es el más serio trabajo presentado en el Congreso, es el menos eufórico, el más elocuente, sensato y carente de demagogia vacua». Trapiello $(1994,276)$ le da la razón, afirmando que, de las ponencias presentadas, fue «una de las más interesantes, por realista y poco retórica (pese a las concesiones hechas al momento [...])». Por su parte, Aznar Soler (1987b, 245) califica la Ponencia Colectiva como el «documento de pensamiento literario más lúcido que hayamos podido leer en esos años». Octavio Paz $(1990,104)^{1}$ dijo en su discurso inaugural del Congreso Internacional de Escritores (Valencia 1987) —celebrado en conmemoración del Segundo Congreso de 1937- que el texto de la Ponencia Colectiva «fue para nosotros el punto de partida de una larga campaña en defensa de la libre imaginación». Y Francisco Caudet $(1984,91)$, en su contribución al Homenaje post mortem a Arturo Serrano Plaja, opina que la Ponencia Colectiva «fue probablemente la más brillante de las presentadas allí».

\footnotetext{
${ }^{1}$ Paz viajó al Segundo Congreso como delegado oficial junto con Carlos Pellicer y José Mancisidor. En el Congreso intervinieron dos delegaciones mexicanas, como Paz (1993, 61-62) puntualiza: una oficialmente invitada, y la otra, de la Liga de Escritores y Artistas Revolucionarios de México, que viajó por su propia cuenta y llegó a España cuando el Congreso ya estaba para terminar. Rafael Alberti sólo menciona en su romance «Los Poetas del Mundo Defienden al Pueblo Español» - leído en la sesión final del Congreso, en Barcelona el 11 de julio de 1937-, a «Mancisidor, Pellicer, Octavio Paz, compañeros» (Schneider 1987, 186). Terminado el Congreso, las dos delegaciones se fundieron en una.
}

Rlit, LXV, 130 (2003), 447-470 
No son estos juicios los únicos en elogiar la Ponencia Colectiva. Sin embargo, no hay que perder de vista que se fundan en intereses y lecturas divergentes que tanto revelan sobre las posturas político-ideológicas de sus autores, como sobre el contenido del texto en sí. Esto se debe a que la Ponencia Colectiva no sólo fue una reflexión sobre el papel del escritor en la sociedad, sino también una toma de posición en un contexto histórico concreto, el de la Guerra Civil Española y la defensa de la República agredida por el fascismo. La celebración del II Congreso Internacional de Escritores para la Defensa de la Cultura en España cobró una importancia singular después de la sublevación militar de verano de 1936, aunque ya se había acordado antes del estallido de la Guerra Civil ${ }^{2}$. En palabras de Octavio Paz (1990, 102):

El Congreso de 1937 fue un acto de solidaridad con unos hombres empeñados en una lucha mortal contra un enemigo mejor armado y sostenido por poderes injustos y malignos. Unos hombres abandonados por aquellos que deberían haber sido sus aliados y defensores: las democracias de Occidente. El Congreso estaba movido por una ola inmensa de generosidad y de auténtica fraternidad; entre los escritores participantes muchos eran combatientes, algunos habían sido heridos y otros morirían con las armas en la mano. Todo esto - el amor, la lealtad, el valor, el sacrificio- es inolvidable y en esto reside la grandeza moral del Congreso.

Pero el Congreso también tuvo sus flaquezas. Fue un congreso inspirado y dirigido por organismos y compañeros de ruta del Partido Comunista, un hecho que incidió fuertemente en la selección de los participantes. La izquierda antiestalinista - los trotskistas y los surrealistas - ya se había visto marginada en el I Congreso Internacional de Escritores para la Defensa de la Cultura de 1935, cuyo presidente de honor fue André Gide. Naturalmente, en una época de crispación ideológica como fue la Guerra Civil Española, las posiciones de poder se volvieron aún más claras. Es así como este ala de la izquierda revolucionaria no estalinista tampoco fue invitada al II Congreso, a pesar de su absoluto apoyo a la República española, y de que Benjamin Péret, uno de los surrealistas más destacados, se encontrara combatiendo en España en el frente de Aragón. Tampoco se invitó a escritores y publicistas anarquistas como, por ejemplo, al anarcosindicalista alemán Augustin Souchy, el cual dirigía la Oficina de Información Exterior de la CNT-FAI en Barcelona y con el tiempo llegaría a ser un escritor libertario notable ${ }^{3}$. Pero el gran ausente del II Congreso

\footnotetext{
${ }^{2}$ Se había acordado en una reunión del «Secretariado general ampliado de la Asociación Internacional de Escritores» en Londres, en junio de 1936, por petición de $\mathrm{Ri}$ cardo Baeza y José Bergamín (Aznar Soler 1987b, 128).

${ }^{3}$ Souchy, un revolucionario imperturbable de Silesia, en sus memorias también cuenta sus vivencias en Barcelona durante la Guerra Civil. Véase Souchy, 1977, 103-123. Rosa Chacel y León Felipe tampoco participaron en el II Congreso (Aznar Soler 1987b, 247 n. 482).
} 
Internacional de Escritores para la Defensa de la Cultura fue André Gide. A pesar de haberse convertido en un sincero defensor de la utopía socialista que parecía realizarse en la Unión Soviética, Gide había dudado mucho tiempo, por temor de perder su libertad de juicio, en aceptar una invitación oficial a un viaje a la U.R.S.S. Finalmente, en junio de 1936, el autor francés emprendió el viaje tanto tiempo aplazado en compañía de algunos amigos, entre los cuales se encontraba el holandés Jef Last —quien participaría en el Segundo Congreso-. El viaje duró más de dos meses y fue un triunfo. Al enterarse de la muerte de Gorki, que había fallecido un día después de la llegada del grupo a Moscú, Gide pronunció una oración fúnebre en la Plaza Roja después de los discursos de Molótov, Bulganin y Alexéi Tolstói. Durante su estancia viajó a Leningrado, al Cáucaso, al Mar Negro y visitó koljoces, fábricas, sanatorios, campos de jóvenes pioneros, una penitenciaría, universidades, jardines de infancia, parques de cultura y museos (Gide 2001, 1317ss.). Anotó las impresiones de sus viajes en cuatro cuadernos que le sirvieron de base para su libro Retour de l'U.R.S.S., publicado a principios de noviembre de 1936. Entre elogios sinceros, Gide criticó en este libro la uniformidad forzada del hombre soviético, la vuelta del espíritu pequeño burgués, la persistencia de grandes diferencias sociales, la falta de libertad artística, el culto a la personalidad de Stalin, la ignorancia del pueblo soviético con respecto a todo lo que existía fuera de la U.R.S.S., la imposibilidad del ejercicio de la crítica en lo fundamental. La publicación del libro, que Iliá Ehrenburg, Aragon y otros trataron de diferir (Gide 2001, 1322), tuvo el efecto del estallido de una bomba. En pocos meses se vendieron más de 100.000 ejemplares. Salieron quince traducciones, entre ellas una al español que se publicó a finales de 1936 en Santiago de Chile y a la que siguieron varias ediciones más (Aznar Soler 1987b, 229 n. 445) ${ }^{4}$. Las críticas dirigidas al Retour de l'U.R.S.S. por parte de los medios afiliados al Partido Comunista y sus compañeros de ruta fueron más que acerbas. De repente Gide se vio aislado del ámbito intelectual que simpatizaba con el comunismo soviético, un ámbito en el que él mismo había sido la estrella por varios años. Como consecuencia de este aislamiento, los organizadores españoles del Segundo Congreso no invitaron a Gide - probablemente obedeciendo también a presiones de la delegación soviética (Aznar Soler 1987b, 228) - a pesar de que con su firma el autor francés se había adherido con entusiasmo a la resolución del Se-

${ }^{4}$ Aznar Soler habla de ocho ediciones en lengua castellana hasta 1938, sin precisar si el libro también se publicó en España ni si siempre se trató de la misma traducción. Según nuestras pesquisas, el libro de Gide fue traducido por Rubén Darío (hijo) y publicado a finales de 1936, bajo el título de Regreso de la U.R.S.S., simultáneamente por la editorial Letras de Santiago de Chile y Sur de Buenos Aires. Parece que en España el libro no se publicó hasta 1982 por Muchnik Editores, Barcelona, en una traducción de Carmen Claudín. 
cretariado de la Asociación Internacional de Escritores para la Defensa de la Cultura, que convocó a sus miembros para el Congreso de Madrid (Schneider 1987, 35).

Gide contestó a sus críticos con la publicación de los Retouches à mon 'Retour de l'U.R.S.S.' pocos días antes del comienzo del Segundo Congreso. En ellos mencionaba esta vez los Procesos de Moscú con sus acusaciones y confesiones abyectas. A raíz de esto en el Segundo Congreso se discutió mucho el asunto Gide entre los participantes. Fue José Bergamín quien, en nombre de la delegación española y las delegaciones hispanoamericanas, expresó en la sesión de Madrid del 8 de julio ${ }^{5}$ su indignación contra los Retouches à mon 'Retour de l'U.R.S.S.' e, implícitamente, también contra el Retour (Aznar Soler; Schneider 1987, 152ss.). Lo que no debe pasar desapercibido es que, con su intervención, Bergamín pedía además a todos los participantés del congreso que marcaran este reproche y esta repulsa con su silencio:

Yo os pido vuestra solidaridad con vuestro silencio para dejar que esta voz mía, precisamente por ser tan débil, vaya a unirse al silencio mismo de la sangre mártir de nuestro pueblo en Madrid para llevar a la conciencia del autor de ese libro esta repulsa y este reproche nuestro (ibídem, 152).

Esta propuesta de silencio a los congresistas por parte de Bergamín resulta especialmente interesante si observamos que un día antes, en la sesión de Madrid del 7 de julio, el delegado soviético Mikhail Koltzov ${ }^{6}$ pronunció un discurso en el que ya condenaba a Gide y sus libros Retour de l'U.R.S.S. y Retouches a mon Retour de L'U.R.S.S. Como señala Schneider (1987, 130 n. 141), entre las diferentes versiones que de este discurso de Koltzov se conocen ${ }^{7}$, tan sólo en la prensa madrileña un día después

\footnotetext{
${ }^{5}$ Anteriormente, en un discurso que expuso en la sesión de tarde del primer día del Congreso, Bergamín estableció una distinción de fondo entre problemas y cuestiones de la cultura española, cuestiones palpitantes, cuestiones vivas y, por consiguiente, mortales, ante la situación que vivía España. Condenó al intelectual hamlético, aislado del pueblo en favor del intelectual en comunión y comunicación con «la sangre popular» (Aznar Soler; Schneider 1987, 24-28). La condena apuntaba a los intelectuales españoles neutrales (Pérez de Ayala, Marañón, Ortega) que, como intelectuales puros, en palabras de Bergamín, sólo eran «traidores despreciables y cabezudos grotescos» (ibídem, 26).

${ }^{6}$ Koltzov fue el representante de la Pravda en España y, posiblemente, agente personal de Stalin (Thomas 1979, 393 n. 5). Posteriormente sería una de las tantas víctimas prominentes de las purgas estalinianas.

${ }^{7}$ Schneider (ibídem) registra las versiones que se publican en $\mathrm{El}$ Sol (8 de julio, 1937, p. 4); International Literature (núm. 8, agosto, 1937, pp. 105-109); Commune (núm. 49, septiembre, 1937, pp. 435-440) y en Diario de la guerra en España (s.l., Ediciones Ruedo Ibérico, 1963, pp. 435-440). El discurso de Koltzov en el Segundo Congreso aparece además en una traducción al alemán en Das Wort (núm. 10, octubre, 1937, pp. 68-74), una revista de literatura alemana del exilio y de oposición al régimen nazi, que entre 1933 y 1945 se editaba en Moscú.
} 
de leerse el discurso en el Congreso no aparecía el ataque directo a André Gide. Llama la atención a este respecto que en una carta a Aznar Soler en agosto de $1976^{8}$ Bergamín se acordara de su intervención en el asunto Gide con las siguientes palabras: "Yo pedí a todas las delegaciones un voto de confianza personal, como presidente de la Asociación española, para hacer uso de la palabra sobre ello antes que ningún otro en la reunión de Madrid» (Aznar Soler 1987b, 359). El propósito de ser el primero en tratar el tema explicaría el hecho de que en la prensa diaria se hubieran omitido los párrafos en los que Koltzov ya criticaba abiertamente a Gide un día antes. Parece ser que el asunto Gide exigiera una declaración oficial por parte de los organizadores del Congreso, es decir, por parte española. Serrano Plaja recuerda en una carta escrita a Aznar Soler en enero de 1978: «No se produjo, como algunas delegaciones poderosas quisieron, especial condenación de Gide, condenación que se quería más o menos abiertamente endosar a la delegación española» (ibídem, 383). Esta condenación exigida por parte de la «poderosa delegación» (ibídem, 383) a la que se refiere Serrano Plaja, de hecho se formulaba en el discurso de Bergamín, pero con su propuesta de silencio asimismo impedía los continuos ataques contra el autor francés durante el Congreso, tal como los atestigua el delegado inglés Stephen Spender en su autobiografía World within world:

Los delegados rusos tenían la consigna de invocar en sus discursos la importancia del papel que Rusia desempeñaba en el Frente Popular, y de denunciar a Trotski y a Gide. Mijail Koltzov, el famoso corresponsal de Pravda, se destacó como improvisador de parodias del Retour de l'U.R.S.S. de Gide (apud Aznar Soler; Schneider 1987, 444).

La delegación rusa incluso pedía la expulsión de Gide de La Alianza Internacional de Intelectuales, a lo cual se opusieron también algunos escritores de la revista Hora de España, como, por ejemplo, Rafael Dieste. En su carta a Aznar Soler en noviembre de 1976, Dieste describe como, junto con Antonio Sánchez Barbudo, fue a pedirle a Bergamín:

el uso de su influjo para evitar la expulsión de Gide de la Alianza Internacional que, proclamada en el Segundo Congreso, habría parecido un rasgo de servilismo por parte de los españoles, y, además en descrédito de quien acababa de hacer las más fervientes declaraciones a favor de la España republicana (apud Aznar Soler 1987b, 371s.).

\footnotetext{
${ }^{8}$ En esta carta, Bergamín atenúa un poco su crítica a Gide en el Congreso de 1937 y muestra, por lo demás, una cierta reticencia «a evocar las cosas pasadas». Lo que sea de cada quien -empleando la expresión atinada de la gente del campo de los mundos novelescos de Juan Rulfo-, si se piensa en el prefacio favorable que Bergamín puso al libro del nunca identificado «Max Rieger» sobre Espionaje en España (1938), en el cual se denunciaron los «crímenes» del POUM y que sirvió de justificación para las acusaciones de sus detractores (Bolloten 1991, 517-518).
} 
El propio Bergamín, en una entrevista con Luis Suñén y César Antonio Molina en el año 1977, explica que su intervención en el Segundo Congreso no fue un ataque contra el escritor francés, que por otra parte estimaba mucho ${ }^{9}$, sino un modo de zanjar el conflicto surgido en torno a la recepción de sus libros en el Congreso:

Yo no le ataqué. La delegación soviética había propuesto expulsarle de la Alianza, cosa que supongo Gide quería. La delegación francesa nos informó de que si esto se llevaba a cabo se retiraba. Se me ocurrió pedir a todas las delegaciones un voto de confianza para que todo se decidiese en el Congreso. [...] Koltzov nos presionaba diciendo que el Congreso se podía celebrar gracias a la protección de la aviación rusa sobre el cielo de Madrid. [...] y dije [...] 'lo mejor ahora es el silencio'. Fue aceptado. Los soviéticos se pusieron contentos y a Gide le llegó al alma (ibídem, 235).

La intervención de Bergamín se publicó en seguida en francés en dos diarios comunistas parisinos (Gide 1950, 196).

Posteriormente, en sus cartas dirigidas a Aznar Soler, también los secretarios del Congreso, Juan Gil-Albert y Arturo Serrano Plaja ${ }^{10}$, recuerdan y comentan el incidente Gide en el Segundo Congreso Internacional de Escritores para la Defensa de la Cultura. Según Gil-Albert, «ese librito, Le retour de l'U.R.S.S. que provocó tales desmanes de expresión no sólo en nuestros cerrados cotos marxistas sino entre los mismos camaradas franceses presididos por Louis Aragon, hizo también mella en mí y en mis amigos, pero no a favor de Stalin, ya que si íbamos a combatir a un dictador casero comprensible es que no modificáramos nuestro enjuiciamiento de fronteras para afuera» (apud Aznar Soler 1987b, 374).

Por su parte, Arturo Serrano Plaja escribe con respecto a la exclusión de Gide del Congreso: «claro está que me pareció entonces y me parece ahora aquella exclusión, una de tantas cosas que hubo que «tragar a la fuerza» (ibídem, 383).

Schneider $(1987,145)$ piensa que la Ponencia Colectiva, leída en el

9 «Siempre admiré mucho, muchísimo a Gide» afirma Bergamín en dicha entrevista (Aznar Soler 1987b, 235). En un artículo de Cruz y Raya de julio de 1935, titulado «Hablar en cristiano», había celebrado la «Défense de la culture» que hizo Gide en su discurso del I Congreso Internacional de Escritores para la Defensa de la Cultura. En este discurso el autor francés, en una crítica - aunque leve- de las propuestas del Realismo Socialista, abogó por una literatura que no se contentara únicamente con imitar, sino que también informara, propusiera, creara (Gide 1950, 92). A Bergamín la defensa de una concepción de la literatura más allá de la exigencia del reflejo le pareció aún - como todo lo demás dicho por Gide en aquella ocasión- de una «luminosa evidencia» (Bergamín 1935, 77).

${ }^{10}$ Parece que, junto con Serrano Plaja y Juan Gil-Albert, también Emilio Prados había sido nombrado secretario del Congreso (Schneider 1987, 60). En su carta del 18 de enero de 1978 dirigida a Aznar Soler, Serrano Plaja, sin embargo, recuerda que «los secretarios de hecho fuimos Gil-Albert y yo» (Aznar Soler 1987, 383). 
Segundo Congreso por Arturo Serrano Plaja, «fue resultado de las discusiones provocadas en torno al libro de Gide». Por varias razones, sin embargo, esto parece ser demasiado simplista. En una carta a Manuel Aznar Soler de 1978, Serrano Plaja afirma que fue él quien tuvo la idea de una Ponencia Colectiva en nombre de la juventud y la sometió antes del comienzo del Congreso al entonces subsecretario de Instrucción Pública, Wenceslao Roces, miembro destacado del Partido Comunista. Éste la aprobó y le encargó a Serrano Plaja redactar el texto. Según Serrano Plaja, el texto se sometió después a discusión de los que, junto a él, irían a firmarlo: Antonio Sánchez Barbudo, Ángel Gaos, Antonio Aparicio, Arturo Souto, Emilio Prados, Eduardo Vicente, Juan Gil-Albert, José Herrera Petere, Lorenzo Varela, Miguel Hernández, Miguel Prieto, Ramón Gaya. Un punto importante a tener en cuenta en la interpretación de la Ponencia es, precisamente, la pertenencia política dé los firmantes, sobre la cual aclara Serrano Plaja también en su carta:

\begin{abstract}
Algunos «militantes del PCE, como Ángel Gaos», firmaron el documento porque se le pidió la firma no en cuanto «militante», sino en tanto intelectual perteneciente - más o menos- a la misma «juventud» que firmó el texto. $\mathrm{Si}$ Miguel Hernández era ya militante del PCE, cosa que ignoro, lo sería de fecha reciente (apud Aznar Soler 1987b, 384).
\end{abstract}

Para señalar después que si Rafael Alberti y Teresa León no la firmaron, fue, por una parte, porque no fueron invitados a hacerlo ya que por su edad no encajaban en el grupo que se configuró para firmarlo, y, por otra parte, porque «su posición política acaso no cuadraba enteramente con algunos de los puntos que la ponencia, de una manera no especialmente sutil, quería dejar establecidos» (ibídem, 384-385). Como se sabe, Alberti era un convencido miembro del Partido Comunista Español. En junio de 1933 había fundado la revista Octubre, que estaba «en contra de la guerra imperialista, por la defensa de la Unión Soviética, contra el fascismo, con el proletariado» (Montero 1977, xvi), y durante la Guerra Civil dirigió El Mono Azul. Hoja semanal de la Alianza de Intelectuales Antifascistas para la Defensa de la Cultura. La relación entre Alberti y Serrano Plaja mostraría durante la Guerra Civil una evolución que quizás sea de interés a la hora de analizar la cuestión de los firmantes, porque no sólo se trata de una cuestión personal, sino en mayor medida política y estética. En 1932 ambos escritores coincidieron en la redacción de $\mathrm{El} \mathrm{Sol}$, precisamente donde Serrano Plaja conoció a Rafael Dieste, Juan Gil-Albert y Ramón Gaya «formando así un núcleo generacional» (entrevista con Caudet 1975b, 15). Más tarde, Alberti, ya militante comunista, fundó la revista Octubre, que, dice Serrano Plaja, «de algún modo canalizó mi evolución política de aquellos días» (Aznar Soler 1987, 379). En El Sol, Alberti escribió el 19 de junio de 1936 una reseña sobre Destierro infinito, de la que Serrano Plaja se le quejó a Caudet años más tarde: 
A Alberti, es la primera vez que lo digo en voz alta, le faltó quizá un poco de generosidad en ese momento. Aunque dice las cosas como son, no lo dice todo. Incluso él, que había iniciado el proceso, no pretendo negarle nada, nunca había intentado hacer lo que yo intenté: una poesía directamente relacionada por dentro, que fuera expresión interna de una preocupación política. Él se contentó con poner en música comunista, digamos, una poesía (1975b, 16).

Lo que muestra el principio de discordancia entre ambos poetas y ambas posiciones estético-ideológicas.

En este punto, resulta importante recordar que la Ponencia Colectiva apareció abruptamente interrumpida en El Mono Azul, el 5 de agosto de 1937, y a continuación se dejó de publicar lo referente al Congreso, precisamente en la transcripción de la Ponencia Colectiva, que se cortaba con la frase: «Los hechos cada vez más son asumidos y resumidos en formas coherentes de pensamiento», dejando sin lugar a los siguientes puntos que Serrano Plaja escribiera y que, acaso, fuera lo que Alberti en su reseña no decía sobre la reflexión poética que Serrano Plaja propugnaba (supra). Aznar Soler le preguntó a Serrano Plaja sobre las posibles causas, a lo que éste contestó: «¿Por qué El Mono Azul dejó de publicar lo relativo al Congreso? No lo sé. Habría que preguntárselo a quienes tenían responsabilidad directa en dicha revista: yo no era uno de ellos» (Aznar Soler 1987b, 385).

De lo que no habla Serrano Plaja es de la ausencia de Rafael Dieste entre los firmantes, quien, como apuntamos más arriba, había configurado ese núcleo generacional junto con Serrano Plaja y Gil-Albert en 1932, además de haber sido uno de los cofundadores de Hora de España. Tal como señala Caudet (1975: 9), los otros fundadores fueron «Antonio Sánchez Barbudo, Ramón Gaya y Juan Gil-Albert. A mediados de 1937, se unieron a ellos en la redacción María Zambrano y Arturo Serrano Plaja». La exclusión de Dieste, por lo tanto, no deja de llamar la atención. Según apunta Trapiello $(1994,276)$, aunque sin señalar las fuentes, Dieste quedó excluido como represalia por la sospecha de simpatizar con los trotskistas. Quizás esta valoración resulte arriesgada, sobre todo teniendo en cuenta que ni el mismo Dieste conoció nunca la razón de que se omitiera su nombre. El 25 de septiembre de 1973, le escribió una carta a Francisco Caudet en la que decía sobre la publicación de las actas del II Congreso en Hora de España:

En ese número mi nombre no aparece, aun cuando yo había contribuido a suscitarlo y había participado en él, no sólo como orador (en representación de Galicia) sino en varios aspectos que no es ahora momento de referir o «novelar». Pues bien, don Arturo, que intervino en la confección del número, me dijo extrañadísimo: «Hay orden de que no figure tu nombre. «¿Tú sabes por qué?»... «No, no sé nada. Pero no te preocupes» (Dieste 1983: 32).

En realidad, cuando se observa el número, se ve que él aparece en calidad de redactor, al igual que Sánchez Barbudo, Gil-Albert o el mismo 
Serrano Plaja, pero donde no aparece es entre los firmantes de la Ponencia Colectiva, a la que Dieste, en su carta, no hace referencia explícita. No fue ésta la única represalia de la que Dieste fue víctima sin aparente explicación. Tal como explica en su misma carta a Caudet, también se le negó el auxilio que le correspondía como «miliciano de la cultura», pese a la mediación de Sánchez Barbudo, y en Barcelona se le excluyó del Comité del Teatro. Más adelante el mismo Dieste se pregunta: «¿fue realmente Roces, en todos los casos, el responsable directo o voluntario de tan extrañas «represalias»? A veces no sé qué pensar» (ibídem, 32). En cualquier caso, fue precisamente Wenceslao Roces quien leyó y aprobó la Ponencia Colectiva antes del Congreso (supra), lo que podría haber dado lugar a algún tipo de consigna contra Dieste.

Entre los firmantes, algunos sólo supieron del proyecto de figurar en una Ponencia Colectiva después de haber llegado a Valencia con ocasión del Congreso. El mismo Serrano Plaja lo afirma contundentemente: «repito, pues: el texto es mío salvo ínfimas enmiendas de detalle. Y es así no sólo porque lo digo yo hoy sino porque así lo dice también a su manera, el texto mismo» (ibídem). Así pues, «con alguna enmienda de tal o cual frase», (ibídem), el texto se aprobó y se eligió a su autor «por unanimi$d a d »$ para leerlo en la sesión correspondiente del Congreso (Aznar Soler 1987b, 384) la cual se celebró en Valencia, el día 10 de julio de 1937.

La Ponencia Colectiva comienza con una justificación de su carácter colectivo $^{11}$. Este carácter, como afirma Serrano Plaja, no se debe a un propósito torpe, fácil y demagógico, «de querer presentar externamente unido, por originalidad, por falso colectivismo, hábilmente preparado, lo que interiormente era disgregado y distinto» (186), sino que surgió de un modo espontáneo, «ya que colectivos y comunes eran nuestros puntos de vista en todas las cuestiones que nos parecieron esenciales y objetivas» (185). La expresión colectiva de la Ponencia es, por encima de las diferencias artísticas y sociales entre los firmantes, algo que crea el momento extraordinario de la lucha común:

ante la guerra, ante la lucha de nuestro pueblo por mantener como enunciado primordial de su contenido su independencia nacional, todo cuanto no es contra-español, todo cuanto no sea traición malvendida al capitalismo sin patria, todo cuanto no sea bursátilmente contrahumano, diríamos, se siente hoy, en España, uno y lo mismo, ante el hecho mismo de la Revolución (186).

${ }^{11}$ En lo siguiente nos basamos para la Ponencia Colectiva en el texto reproducido en Aznar Soler; Schneider (1987, 185-195) que hemos cotejado con el original, publicado después del Congreso en Hora de España 8 (1937). Las citas remiten a esta reproducción, indicando entre paréntesis la página correspondiente de la documentación de Aznar Soler; Schneider. No obstante la rectificación de algunos errores de imprenta, la reproducción de Aznar Soler; Schneider no ha podido subsanar los sinsentidos que el texto evidencia en algunos lugares. 
¿Por qué esta justificación del carácter colectivo de la Ponencia y qué significa en este contexto el remitirse como factor aglutinador a la Revolución? En el momento histórico, en el cual Serrano Plaja lee la Ponencia Colectiva, el colectivismo era un tema altamente controvertido, tanto artísticamente como desde un punto de vista político y social. Artísticamente, el debate alrededor del colectivismo se había intensificado a partir del Primer Congreso de Escritores Soviéticos de 1934, en el cual se enunciaron las líneas directrices del Realismo Socialista ${ }^{12}$. En su discurso del I Congreso Internacional de Escritores para la Defensa de la Cultura, Gide se pronunció en favor del individualismo del escritor, asintiendo a la vez plenamente a la idea del comunismo (Gide 1950, 85). El tema también estuvo presente en las reacciones al I Congreso que se publicaron en España (Aznar Soler 1987a, II 591-758). Se trataba de aunar la libertad del pensamiento y la expresión con la subordinación a las consignas del Partido Comunista, a las que, en un gesto de desafío, había suscrito Rafael Alberti con su poemario Consignas de $1933^{13}$. Serrano Plaja, quien junto con Julio Álvarez del Vayo y Andrés Carranque de Ríos había integrado la delegación española que asistió al I Congreso Internacional de Escritores para la Defensa de la Cultura (Aznar Soler 1987a, I 30), buscaba fijar un equilibrio entre la individualidad artística del escritor y la lucha «para poder llegar al hombre», una lucha que para el Serrano Plaja de aquel entonces sólo se podía librar «al lado de algo tan concreto como significa el Partido Comunista» ${ }^{14}$. Con la sublevación militar contra la República de julio de 1936, la tensión entre la individualidad del escritor y la colectividad había tomado un cariz nuevo. Ahora se imponía la cuestión de si la actividad artística tenía la prioridad de plasmar la lucha contra el enemigo común o si, por el contrario, debía antes que nada seguir manteniendo su ambición estética ${ }^{15}$. Sin embargo, el apoyo de Serrano Plaja al Partido

\footnotetext{
${ }^{12}$ Para este congreso consultamos la documentación de Schmitt; Schramm (1974), en especial el largo discurso de Karl Radek, en el cual, probablemente por orden de Stalin, se exigía la superación del individualismo del escritor compañero de ruta del comunismo.

${ }^{13}$ De este poemario de Alberti existe un comentario de Serrano Plaja que examina Caudet $(1984,75-76)$.

${ }^{14}$ Citamos de un carteo abierto entre Serrano Plaja y Bergamín que, motivado por el ya mencionado comentario de Bergamín en Cruz y Raya sobre el discurso «Défense de la culture» de Gide, se había publicado primero en la revista Leviatán de Luis Araquistain y luego en Cruz y Raya 32 (1935), de donde procede la cita. Bergamín reprodujo el discurso de Gide, su propio comentario, «la réplica de Serrano Plaja y su ulterior respuesta a éste en un librito titulado Defensa de la cultura, precedido de unas palabras suyas fechadas en abril de 1936» (Aznar Soler 1987a, 180 n. 185).

${ }^{15}$ Esta discusión sobre el arte al servicio de la lucha ya ocupó un lugar privilegiado a partir del primer número de Hora de España, en la sección de «Notas», y se materializó en el intercambio de cartas abiertas entre Ramón Gaya, pintor, y José Renau, cartelista, sobre los carteles de exhortación revolucionaria del bando republicano. El
} 
Comunista, sólo se puede entender plenamente al observar la posición que éste tuvo en España durante la Guerra Civil, así como su gran poder -y evidentemente el de la misma U.R.S.S.- sobre el Gobierno de la República. Así, no está de más tener en cuenta que si el 18 de julio de 1936, el Partido Comunista contaba entre 20 y 30.000 miembros en todo el Estado, a principios de 1937 había crecido hasta la cifra de 200.000, que aún se quintuplicaría hacia mediados del mismo año (Jackson 1999: 316), es decir, alrededor de la fecha en que se celebró el Congreso de Valencia. Tal crecimiento se debía sin duda a la forma eficiente en que el Partido Comunista actuó en la defensa de Madrid, así como a la animosa presencia de comunistas importantes en los medios de comunicación, como lo era Dolores Ibárruri (Preston 1999); pero, sobre todo, por la gran ayuda económica que le llegaba a la República desde la U.R.S.S. frente a la negligencia de los países democráticos occidentales. Esto hacía que la dependencia del gobierno con la política soviética, canalizada por el PCE, fuera casi absoluta. No obstante, durante toda la guerra se dio una suerte de pulso de poderes entre ambas partes. El PCE ganó adeptos no sólo entre la clase trabajadora, sino también entre algunos burgueses - gracias a la oposición a las revoluciones locales y colectivistas y la protección de la propiedad-, y también entre muchos intelectuales que habían quedado impresionados ya a principios de los años treinta por la Rusia Soviética. Pero al mismo tiempo:

La expansión comunista provocó muchos recelos del ala caballerista del Partido Socialista. Los intelectuales más destacados, como Luis Araquistain, así como la mayoría de los más antiguos funcionarios de la UGT, temían que los comunistas fueran un caballo de Troya que acabara destruyendo el verdadero programa revolucionario español en favor de una burocracia estalinista y una política extranjera puesta al servicio de los intereses exclusivos de la Unión Soviética (Jackson 1999: 317).

A raíz de la caída de Málaga el 10 de febrero de 1937, que desencadenó una serie de destituciones importantes, se comenzaron a aproximar los republicanos de clase media, socialistas moderados y comunistas. «La alianza se basaba en una defensa a ultranza de Madrid, la contención de la revolución proletaria, la necesidad de un Gobierno de guerra fuertemente centralizado» (ibídem, 321) y sobre todo la afirmación de que Largo Caballero debía dimitir. El 17 de mayo de ese mismo año cayó Largo Caballero y fue reemplazado por Juan Negrín, lo que era un paso en la direc-

primero criticaba la producción de carteles fría y práctica, «escudándose en exigencias comerciales o industriales» mientras apoyaba un arte libre (HdE I, 54-56); mientras que el segundo abogaba por la objetividad y el despojamiento de toda emotividad personal para llegar a las masas con un objeto ( $H d E$ II, 57-60). El primero firmó la Ponencia Colectiva, pero el segundo no, lo que sin duda tiene su importancia en este punto. 
ción deseada por los comunistas. Así pues, en la medida en que las tensiones en el campo republicano se agudizaban hasta el desenlace sangriento en Barcelona a principios de mayo de 1937, en el cual el anarquismo y el socialismo antiestalinista fueron definitivamente eliminados del poder (Preston 1996, 184-190), todo lo que sonaba a colectivismo adquirió una connotación negativa. Colectivas habían sido las ocupaciones de fábricas y terrenos en Cataluña, Aragón y otras partes de la zona republicana y colectivas fueron sus autogestiones (Bernecker 1978). Ahora estas formas de colectivismo resultaban ser erróneas, si no peligrosas para quien las profesaba. Es así como la justificación del carácter colectivo de la Ponencia, leída por Serrano Plaja en el II Congreso Internacional de Escritores para la Defensa de la Cultura, no solamente proclamaba la comunidad de los escritores jóvenes por encima de sus divergencias artísticas y sociales, sino que también se esforzaba, aunque de forma indirecta, por tomar sus distancias con respecto al colectivismo libertario.

Aproximadamente al mismo tiempo, en que había concebido la idea de la Ponencia Colectiva, Serrano Plaja escribió un artículo que luego publicó en Hora de España VII (julio 1937), en el cual polemizaba con otro de Rosa Chacel, incluido en el mismo número de la revista, en defensa de los ideales libertarios. El artículo de Rosa Chacel, «Carta a José Bergamín sobre Anarquía y Cristianismo», que ella le escribió en forma de una carta abierta, se refería directamente a otro artículo que éste había publicado en abril de 1937 en la revista francesa Esprit, bajo el título: «Pour rien au monde (Anarchisme et catolicisme)». Rosa Chacel criticaba en su artículo el uso que Bergamín hacía del término anarquía, nada «más que en calidad de improperio, como es uso en el lenguaje parlamentario» (Chacel 1937, 16), y para señalar todo lo que fuera una perturbación del orden, pero, sobre todo, que Bergamín resumiera «en la palabra anarquía, por aquella su faceta negadora, todo lo que en la Iglesia se niega y descompone» (ibídem). A Rosa Chacel le interesaba la realidad del «porvenir espiritual» (ibídem, 14) de la anarquía y estaba convencida de que «toda la filosofía española, la que Unamuno considera «la única verdadera y propiamente tal», es fundamentalmente, por encima de toda opinión, anarquista» (ibídem). Esta convicción quería llevársela también a otros intelectuales españoles con sus publicaciones en Hora de España, que tuvieron una buena acogida en periódicos anarquistas ${ }^{16}$. Tenía la intención de organizar un seminario que se

${ }^{16}$ En el artículo Chacel también hacía alusión a un ensayo sobre Unamuno, titulado Dios insiste en España, que en febrero de 1937 leyó como conferencia en la Casa de la Cultura en Valencia. Este ensayo se escribió para la revista Das Wort (véase op.cit. 7), pero no llegó a publicarse en ella, ya que al parecer el concepto de anarquía de la autora no cuadró con la posición ideológica de la revista: «pensando que mis palabras, al salir de nuestra tierra, caerían en un medio en el que ninguna mala inteligencia podría enturbiar su objetividad, fuí en ellas más explícita. Y aquí sí que puedo decir que topé 
dedicara a estudiar la idea anarquista, especialmente «en su raigambre originaria, en religiones y filosofías» (ibídem, 15), para fundar con ello una escuela. Para ello, instó a los escritores a que acudieran a la llamada a los intelectuales que hizo Solidaridad Obrera. Con esto se refiere a un intento por parte de Jacinto Toryho, entonces director de la revista, de transformar la publicación anarquista, buscando la colaboración de intelectuales, siempre que no fuese demasiado crítica. En eso se parece al afán de Chacel, que pretendía «acercar el partido anarquista a un grupo de intelectuales que mantuviese conexión con el movimiento popular, pero enteramente abstenido de toda actividad política» (ibídem). Toryho finalmente sólo encontró la cooperación del viejo geógrafo Gonzalo de Reparaz, del escritor Eduardo Zamacois y del periodista radical Salvador Cánovas Cervantes (Tavera 1992, 97-98). No se puede decir que tal llamamiento tuviese el éxito esperado por Toryho, y tampoco lo tuvo en el caso de Chacel, que abandonó el proyecto y acabó por irse a París a trabajar «en una, aunque externa, tranquilidad» (Chacel 1937, 15). En cualquier caso, al contrario de la actividad revolucionaria de Solidaridad Obrera, Rosa Chacel defendía tan sólo el concepto filosófico de la anarquía, en un momento, en el cual, con la formación del gobierno de Juan Negrín el 17 de mayo de 1937, el anarquismo, políticamente, se vio definitivamente desbancado. Al final de su alegato la autora afirmaba:

Anarquía no es desorden ni resentimiento. No es desorden, porque orden - ya lo dije en otra ocasión - es un concepto meramente ordinal, anárquico [...] Y no es resentimiento porque es, en su comienzo, justicia: esa palabra diluvial. $\mathrm{Y}$, al final, después del diluvio de sangre, es amor. Amor de nada abstracto. Amor del que nace en la sangre ante la sangre (ibídem, 26).

Serrano Plaja, por su parte, en el antes mencionado artículo de respuesta en Hora de España, titulado «A diestra y siniestra», criticaba que con su concepto de anarquía la autora no quería tener en cuenta los hechos reales, «la significación precisa de esa palabra en España» (Serrano Plaja 1937a, 31). Aludía abiertamente a «los sucesos de Barcelona» (ibídem, 34), rechazando categóricamente el anarquismo o la anarquía como «aquella parte de nuestro pasado que nos estorba para la realización de nuestro porvenir» (ibídem, 42). Según Serrano Plaja:

El escritor vuelve a ocupar su puesto entre millones de hombres en marcha, vuelve a ser útil de acuerdo con sus posibilidades; y es útil a la revolución, que se realiza ineludiblemente, con toda la dignidad que ha tenido en los mejores momentos del mundo, del hombre. Todo lo que sea oponerse a la revolución, al como ésta es, realmente, es oponerse a que las cosas sean como son (ibídem).

con la Iglesia; el ensayo escandalizó a quien me lo había pedido» (ibídem, 15). A pesar de las pesquisas realizadas, no logramos encontrar el ensayo referido, que probablemente nunca llegó a ser publicado. 
Apuntaba, además, que la realidad de la revolución en España era «la revolución organizada» de la «clase obrera organizada», la cual «significa el agotamiento, afortunadamente, y cada día más, del anarquismo indolente e individualista de todo el pasado español» (ibídem).

Esta revolución, a la que, según Serrano Plaja, el escritor volvió a ser útil, era la Revolución con mayúscula de la Ponencia Colectiva ante la cual todos se sentían unos y los mismos. No era la revolución libertaria, estallada espontáneamente después del levantamiento militar de julio de 1936, o, por lo menos, no lo era en su esencia, sino «la totalidad histórica del fenómeno que alcanza sus máximas dimensiones, su dramática plenitud, en la lucha actual del pueblo español contra el fascismo internacional» (187). En concreto, sin embargo, la Revolución en España, como en otras partes, ya se había convertido en lucha intestina. Además de la represión contra el anarquismo, el 16 de junio fueron detenidos cuarenta miembros del POUM, Andrés Nin entre ellos. A éste lo separaron del resto de prisioneros y desapareció. A pesar de los intentos difamadores del PCE en los que se relacionaba el POUM con los servicios secretos de los nacionalistas, y por los que se negaba conocer el paradero de Nin, se acabó sabiendo que había sido encerrado en la cárcel del NKVD de Alcalá de Henares, interrogado y torturado por Orlov. Parece ser que Negrín y Orujo exigieron en vano responsabilidades a sus ministros comunistas mostrando su molestia frente a este atentado contra la justicia democrática (Jackson 1999, 531), frente a la alegría que despertó la liquidación del POUM entre célebres comunistas como Dolores Ibárruri, que vieron en ello un paso hacia la fusión con el PSOE. Al igual que con el gobierno de Largo Caballero, el PCE seguía intentando unirse con los socialistas ahora que estaba Negrín en el poder, sin embargo, tal como señala Preston, este altercado obstaculizó todo posible proceso $(1999,394)$. Es más, Negrín destituyó al General de Seguridad, quien había cooperado con Orlov, y creó el Servicio de Inteligencia Militar dirigido por un socialista a mediados de agosto:

Mientras tanto, los consejeros rusos comenzaron a ser cambiados cada vez con mayor frecuencia, y era un secreto a voces que muchos de ellos habían sido fusilados tras regresar a su país. Los envíos de armas rusas habían disminuido rápidamente, tanto por razones prácticas como políticas, y el Gobierno ordenó poner discretos carteles en Barcelona y Valencia pidiendo al pueblo que no hablara mal de Rusia y que recordara que la Unión Soviética era la única gran potencia que había ayudado a la República (Jackson 1999: 352).

De ahí que la palabra «Revolución» que emplea Serrano Plaja en la Ponencia Colectiva, se situara en un contexto de discusiones, luchas de poder, e intentos fallidos de fusiones y eliminaciones políticas dentro del bando republicano, que la convirtió en un concepto altamente controvertido y necesitado de precisión. 
Es obvio que Serrano Plaja en la Ponencia Colectiva se esfuerza por llevar «la actual lucha del pueblo español», de acuerdo con las líneas directrices del II Congreso, a dos dimensiones más amplias que sobrepasaban los límites de la mera defensa de la República contra la sublevación armada de algunos generales desleales. Por un lado estaba la lucha contra el fascismo internacional, cuya intervención en la contienda española sólo era una, aunque por el momento la más grave, de las muchas expresiones de su carácter destructor, profundamente antihumano. A este respecto es reveladora la resolución final aprobada por el Segundo Congreso de Escritores para la Defensa de la Cultura en París, el 18 de julio de 1937. En ella los escritores de ventiocho naciones proclaman como primer punto «que la cultura que se han comprometido a defender, tiene por enemigo principal al fascismo». En segundo lugar declaran estar dispuestos a luchar contra el fascismo con todos los medios disponibles, «ya cuando muestre abiertamente su rostro destructor, o adopte, para llegar a sus fines, formas desviadas». Por último hacen constar «que en la guerra efectiva que el fascismo ha abierto contra la cultura, la democracia, la paz y, en general, la felicidad y el bienestar de la Humanidad, ninguna neutralidad es posible» (Aznar Soler; Schneider 1987, 315-316). Por otro lado, la lucha del pueblo español implicaba también el proceso de la Revolución, la que «por lo menos a partir del año 17» influía en —si acaso no coincidiera con- «toda la vida española» (187).

Por lo que hemos visto más arriba, la mención en este contexto del año 17 resultaba ser calculadamente ambigua. Por una parte, apuntaba a la gran crisis social de 1917 que sacudió los fundamentos del sistema político español culminando en una huelga general orquestada por los socialistas y que llevó, en sus últimas consecuencias, a la proclamación de la República en 1931 (Preston 1996, 19-23). Este proceso revolucionario continuó en los años posteriores y podía conceptualizarse, en la perspectiva marxista, como la consumación de la revolución democrática burguesa en España, ahora amenazada por la contrarrevolución fascista. Por otra parte, la mención del año 17 aludía también a la Revolución de Octubre, la revolución socialista por antonomasia, que, excediéndolas, había incorporado las conquistas de la revolución democrática burguesa. Vistas las circunstancias, el texto de la Ponencia Colectiva no concreta más el contenido de la palabra Revolución que profusamente maneja. Sólo se propone caracterizar un aspecto, el cual, según Serrano Plaja, precisa y rigurosamente define la juventud española, en cuyo nombre él se pronuncia (188).

Este aspecto es el antagonismo entre razón y voluntad, que en España, en la opinión de Serrano Plaja, se ha manifestado como la oposición entre «los comentaristas y los puros», por un lado, y «un confuso revolucionarismo», por el otro (ibídem). Con la expresión «los comentaristas y los puros«, Serrano Plaja quería denunciar al mismo tiempo a los observado- 
res distanciados de las circunstancias españolas que, como Ortega y Gasset, se situaban au-dessus de la mêlée, como a los representantes de la poesía pura, cuyos ideales artísticos, a partir de 1930, cada vez más se veían puestos en tela de juicio (Cano Ballesta 1972). Por otra parte, con señalar la existencia de «un confuso revolucionarismo», Serrano Plaja criticaba las manifestaciones de una adhesión confusa a la idea de la Revolución. En sus palabras: «Lo puro, por antihumano, no podía satisfacernos en el fondo; lo revolucionario, en la forma, nos ofrecía tan sólo débiles signos de una propaganda cuya necesidad social no comprendíamos y cuya simpleza de contenido no podía bastarnos» (188). La contradicción entre el antihumanismo de lo puro, identificado con la razón, y la simpleza de contenido de la propaganda revolucionaria, adscrita a la voluntad, sólo podía resolverse por un arte que no se contentase como el arte de propaganda con el simple gesto revolucionario, sino que respondiese «ideológicamente al mismo contenido humano de esa Revolución» (189) ${ }^{17}$.

Es aquí, a través del rechazo del arte de propaganda a favor de un arte verdaderamente revolucionario que no sólo representase «a los obreros buenos, a los trabajadores sonrientes» (190), sino a su calidad de hombres «con pasiones, con sufrimientos, con alegrías mucho más complejas que las que esas fáciles interpretaciones mecánicas desearían» (ibídem), donde se podría establecer un nexo con la posición de Gide que ha querido ver Schneider $(1987,145)$. No con el Gide del Retour de L'U.R.S.S., y mucho menos aún con el de los Retouches à mon 'Retour de L'U.R.S.S.', sino con el Gide del discurso del I Congreso Internacional de Escritores para la Defensa de la Cultura con su advertencia contra un concepto demasiado estrecho del arte, que solamente estuviese orientado hacia las necesidades momentáneas de una clase o época (Gide 1950,94$)^{18}$. Pero este nexo, si de verdad existía, era más bien débil y, de todas formas, menos importante que el compromiso de Serrano Plaja con la lucha «para poder llegar al hombre» al lado del Partido Comunista —en la medida en que esto significaba la premura de ganar la guerra-, ya expresado en su carta abierta a Bergamín. Y este compromiso, en su opinión, en el momento actual de la guerra, llevaba a la desaparición de la oposición entre «la realidad objetiva y el mundo íntimo» (190) o, a un nivel más general, a la compenetración de razón y voluntad:

${ }_{17}$ Como ya se vio, una de las manifestaciones de este arte de propaganda fueron los carteles revolucionarios, a los que Ramón Gaya, miembro de la redacción de Hora de España, había reprochado, en el primer número de la revista, su falta de emoción artística (Gaya 1937, supra n. 15), véase también Gaya; Gil-Albert (1937).

${ }^{18}$ Existen otras declaraciones de Gide de aquellos años que expresan la misma preocupación por la independencia del arte y la literatura, véase el discurso «Littérature et Révolution», pronunciado en 1934 en París después del I Congreso de Escritores Soviéticos (Gide 1950, 56-61). 
Porque hoy la revolución [sic] española lucha por la nada desdeñable —contra lo que creen ciertos apasionados- organización racional de su existencia, por el acoplamiento, conforme a razón, de un mundo que excluya el desorden racionalmente capitalista, inhumanamente monopolista, pero, además, lucha con toda su voluntad, con todo el esfuerzo de su mayor pasión posible: la pasión que se sabe consciente y razonable, la pasión que sabe que tiene razón (191).

La organización racional, por la cual, según Serrano Plaja, luchaba la Revolución española, implicaba, otra vez, una crítica indirecta al anarquismo libertario por su falta de organización racional y por la oposición que mostrara contra la República democrática y a favor de la Revolución libertaria (Vidal 1996, 105), por más que coincidiera — como, desde luego, el ideario del POUM - con la meta de la abolición del «desorden racionalmente capitalista». «Hoy en España», continúa Serrano Plaja, refiriéndose obviamente al momento después de la eliminación de los anarquistas y comunistas antiestalinistas del poder, «nuestra lucha, en todos sus matices, responde a un contenido de pensamiento con una expresión de voluntad. Los hechos, cada vez más son asumidos y resumidos en formas coherentes de pensamiento» (191). A nivel del arte y la literatura, esto significaba que se producía «una poesía poética, absoluta, en cuanto a calidad, y una pintura y una creación intelectual, en suma cada vez más apasionada y cada vez más inteligente» (ibídem).

En el centro de esta actividad poética y artística debía situarse el hombre, no en algunos de sus aspectos inmediatos apelados por el arte de propaganda, sino en la totalidad de sus experiencias y valores, actualizados por la Revolución. El arte de propaganda, por sí solo, era insuficiente. Sólo valía como camino para llegar al fin que se proponía la Revolución. En palabras de Serrano Plaja:

Lo demás, todo cuanto sea defender la propaganda como un valor absoluto de creación, nos parece tan demagógico y tan falto de sentido como pudiera ser, por ejemplo, defender el arte por el arte o la valentía por la valentía. Y nosotros queremos un arte por y para el hombre y una valentía miedosa, que sólo es valentía en tanto que tiene un motivo para serlo, en tanto que tiene un comienzo esforzado, para llegar a un fin victorioso. El valiente de otra manera, corre el peligro de la chabacana valentía sin objeto, de la valentía profesional (192).

El rechazo repetido del arte de propaganda que se desprende de esta cita, debe verse en relación a la poética que Serrano Plaja, influido por la poesía sin pureza de Neruda, venía desarrollando desde antes de la Guerra Civil. Al redactar el texto de la Ponencia Colectiva, aún trabajaba en la confección de su poemario El hombre y el trabajo que finalmente salió en $1938^{19}$.

\footnotetext{
${ }^{19}$ De este poemario hay una reimpresión, acompañada por una larga introducción de Francisco Caudet que explicita la formación y las líneas directrices de la poética del autor, véase Serrano Plaja (1978, XI-LXXIX).
} 
En este poemario trataba de aunar su ética comprometida con una estética que decía en un tono a la vez sencillo y elevado los oficios (enajenados por el capitalismo), que constituyen el ser del hombre, el impacto destructor de la guerra y el recuerdo de la experiencia del amor ${ }^{20}$. Esta poesía estaba lejos de los miles de versos escritos espontáneamente a raíz de la guerra y publicados en revistas, periódicos y folletos «como medio de propaganda dentro del propio campo, o como arma para convencer al enemigo de que no combatía en el lado justo» (Pérez-Ramos 1990, 99). Mientras que al principio de la contienda esta poesía con su escritura dominaba casi toda la producción poética en la zona republicana, a mediados de 1937 ya se había abierto un abismo entre los poetas de oficio y los poetas no profesionales, que a veces se expresaba en forma polémica y que explica el rechazo del arte de propaganda en la Ponencia Colectiva (ibídem, 106-107).

Es así como la estética profesada por Serrano Plaja no debe tomarse - o, por lo menos, no debe tomarse primordialmente - como una crítica implícita del Realismo Socialista como lo quiere Octavio $\mathrm{Paz}^{21}$, sino como un distanciamiento dirigido contra una poesía y un arte del momento ya llevados a la marginación por la política cultural oficial.

El arte por y para el hombre que reclama Serrano Plaja en nombre de los jóvenes escritores de la Revolución, tampoco excluía a la tradición. Al contrario, quería aprovecharse «de todo cuanto en el mundo ha sido creado con esfuerzo y clara conciencia, para, esforzadamente, enriquecer [...] esa claridad creciente del hombre» (193). Esto vuelve a recordar al discurso de André Gide del 13 de junio de 1935, «Défense de la culture» - a pesar de que, como se ha visto, el escritor francés hubiera acabado por caer en desgracia. En «Défense de la culture», Gide escribía sobre la cultura anterior:

por artificial que pueda ser, ha producido obras admirables. Es absurdo e inútil negar el pasado. Incluso diría que la cultura con la que hoy soñamos, sin duda no podrá realizarse en seguida y que sin duda será bueno que primero haya existido esta cultura engañosa. Igual que, por detestable que nos parezca el régimen capitalista, sin duda deberá preceder al régimen comunista que queremos $(1950,90)^{22}$.

Es decir que la cultura anterior también hacía posible la cultura del momento, y Gide fue a continuación aún más allá, al señalar que a partir del comunismo, la cultura y la civilización debían desarrollarse y exten-

\footnotetext{
${ }^{20}$ El poema «Estos son los oficios», que abre la serie de los oficios humanos evocados en el poemario de Serrano Plaja, había sido publicado en una primera versión en la revista Caballo verde para la poesía de Neruda (Ibarra, 2000, 99-108).

${ }^{21}$ Esta crítica también se pone de relieve en el estudio, por otra parte meritorio, de Görling $(1986,304)$, quien ha examinado en profundidad las relaciones contradictorias entre proceso político y práctica estética durante la Guerra Civil.

${ }^{22}$ Traducción del francés de Daniela Pérez y Effinger.
} 
derse. En la Ponencia Colectiva, Serrano Plaja quería asimismo recoger «la herencia del humanismo burgués, menos lo que este último tiene de utopía, de ilusión engañosa sobre el hombre y la sociedad, de pacifismo, de idealismo en desuso y casi pueril» (92), lo que acaso remita a la cita de Gide. Pero Serrano Plaja lee su ponencia precisamente en tiempos de guerra, cuando todo cobra un significado si no diferente, sí más urgente:

no podemos fiarnos de un progreso que se hiciera por sí sólo; no podemos admitir el pacifismo en esta época de guerra, que sólo nos permite entrever el fin de las guerras capitalistas y el advenimiento efectivo de la paz, por la revolución (ibídem).

A continuación, refiriéndose a un ensayo temprano de Unamuno titulado «La dignidad humana» ${ }^{23}$, Serrano Plaja especifica que el humanismo que entienden realizar los firmantes de la Ponencia Colectiva consiste en «el intento de restituir al hombre la conciencia de su valor, de trabajar para limpiar la civilización moderna de la barbarie capitalista [...]» (ibídem). Con atenerse al joven Unamuno anticapitalista, quien en su ensayo había criticado la degradación del hombre a un valor de cambio, Serrano Plaja cierra el círculo de la tradición como él la entiende. La juventud de la crisis de fin de siglo y la juventud surgida de la Revolución se dan la mano reivindicando una herencia humanística liberada de las taras de la alienación ${ }^{24}$.

Porque todos los firmantes de la Ponencia Colectiva eran jóvenes intelectuales del momento, en su mayoría colaboradores regulares de la revista Hora de España de distinto signo político. No en vano hace Serrano Plaja hincapié en la naturaleza de los firmantes como miembros de la Alianza de la Juventud, término utilizado ad hoc en un Congreso organizado por la Alianza de Escritores Antifascistas de preponderancia comunista. Y así como en la lucha, el humanismo del que habla la Ponencia Colectiva, debe estar unido al pueblo español, se entiende al bando republicano, y en ese sentido se afirma: «De ese humanismo implicado así en nuestra lucha, nos consideramos nosotros activos militantes. $\mathrm{Y}$ ponemos a

${ }^{23}$ El ensayo «La dignidad humana» había sido publicado por primera vez en 1896 en la revista Ciencia Social de Barcelona. Unamuno lo recogió en la edición en siete volúmenes de sus Ensayos (1916-1918) en la que Serrano Plaja probablemente lo leyó. Consultamos el texto del ensayo en las Obras Completas de Unamuno de la editorial Escelicer, reunidas por Manuel García Blanco.

${ }^{24}$ En Hora de España 4 (abril 1937) se publicó un artículo de José F. Montesinos, en el que ya se propone a la «juventud que se proclama revolucionaria» un rescate del pensamiento del rector fallecido de la Universidad de Salamanca, quien había criticado la República y saludado la sublevación militar de julio de 1936 - por lo que fue destituido de su cargo por Manuel Azaña, Presidente de la República- pero quien en el incidente tan sonado del 12 de octubre de 1936 en el paraninfo de la universidad salmantina protestó valientemente contra las injurias del general Millán Astray, lo que le valió una segunda destitución, esta vez firmada por Franco (Aznar Soler 1987b, 92-95). 
contribución, para afirmarlo, cuanto nos es dable: Desde nuestra voluntad a nuestra juventud» (93). Es decir, los firmantes de la Ponencia Colectiva ponen al servicio del bando republicano tanto su trabajo intelectual, del que la revista Hora de España dejó constancia, como su esfuerzo como hombres jóvenes en la lucha. Una lucha cuya mayor urgencia era precisamente ganar la guerra. Y ganar esa guerra significaba para ellos también «conquistar la categoría de hombre, la dignidad humana» (94).

Con esto encaja la declaración final de la Ponencia Colectiva, en la cual los firmantes se comprometen a luchar «allí donde el pueblo español, del que esperamos todo, nos diga, a través de sus órganos de expresión democrática, allí donde nos diga el Gobierno español, que es hoy algo mucho más importante que un gobierno» (195) ${ }^{25}$. Si la urgencia en julio de 1937 era ganar la guerra, Serrano Plaja como los demás creían que tan sólo se podría conseguir con la ayuda de la U.R.S.S. Sin embargo, en la Ponencia Colectiva, de una forma soterrada, se observa cierto distanciamiento de la política soviética en España, o por lo menos una pretensión de independencia intelectual, que se manifiesta en las posibles referencias al Gide de la Défense de la culture y al joven Unamuno, en las reflexiones sobre el arte, la tradición y el humanismo. Eso no quita que en otros puntos coincidieran claramente con la política del PCE, como evidencian las críticas al anarquismo, que - como se ha visto (supra) - ocupaba parte de la atención de Serrano Plaja en aquel momento ${ }^{26}$. Ni niega que quizás algunos intelectuales jóvenes no hubieran podido firmar, respondiendo a las consignas marcadas por el poder del PCE.

Sin embargo, por esa autonomía intelectual y política que Serrano Plaja intentaría manifestar y mantener en la Ponencia, se podría explicar el último párrafo: «Así, con una responsabilidad serena y consciente y voluntaria disciplina, queremos colaborar con nuestro pueblo a ganar la guerra, a conquistar por ese único hecho, sólo y sencillamente: el hombre» (95). Es decir que, a pesar de la lucha ordenada y orquestada por el gobierno republicano, y su necesaria ayuda soviética, se manifiesta su pretensión de conquistar la dignidad humana. Un humanismo que, con raigambre en la tradición, debía derivar en un humanismo valiente ligado a la lucha del

\footnotetext{
${ }^{25}$ El alineamiento explícito de los firmantes de la Ponencia Colectiva al lado del Gobierno español no debe sorprender demasiado. Al fin y al cabo, fue el Ministerio de Instrucción Pública, dirigido por el comunista Jesús Hernández, el que financiaba el Congreso. Juan Negrín, el flamante Presidente del Consejo, pronunció el discurso inaugural (Aznar Soler; Schneider 1987, 15). Además, como ya se vio, dos de los firmantes, Arturo Serrano Plaja y Juan Gil-Albert, eran los secretarios oficiales del Congreso.

${ }^{26}$ Pero es que no se puede olvidar que para los socialistas y los comunistas, las actuaciones independientes e incontroladas de los libertarios, sí que suponían un obstáculo al objetivo principal de ganar la guerra, como por ejemplo el intento de Durruti de atracar el Banco de España para costear su propia revolución al principio de la Guerra Civil (Vidal 1996, 213-215).
} 
pueblo. Lo que enlazaría con el proyecto intelectual, cultural y plural de la revista Hora de España, y del grupo generacional que la fundó.

\section{BIBLIOGRAFÍA}

A. Textos y documentos

AZNAR SOlER, Manuel; SCHNEIDER, Luis-Mario (1987): II Congreso Internacional de Escritores para la Defensa de la Cultura (Valencia-Madrid-Barcelona-París 1937), vol. III: Actas, ponencias, documentos y testimonios. Valencia: Generalitat Valenciana, Conselleria de Cultura, Educació i Ciència.

BERGAMín, José ( 1935): «Hablar en cristiano». En: Cruz y Raya 27 (julio 1935), 73-83.

CHACEL, Rosa (1937): «Carta a José Bergamín sobre anarquía y cristianismo». En: Hora de España 7 (julio 1937), 13-26.

GAYA, Ramón (1937): «Carta de un pintor a un cartelista». En: Hora de España 1 (enero 1937$), 54-56$.

-, Y Gil-Albert, Juan (1937): «Cartas bajo un mismo techo». En: Hora de España 6 (junio 1937), 22-32.

GIDE, André (1950): Littérature engagée. Textes réunis et présentés par Yvonne Davet. Paris: Gallimard.

-, (2001): Souvenirs et voyages. Edition présentée, établie et annotée par Pierre Masson, avec la collaboration de Daniel Durosay et Martine Sagaert. Paris: Editions Gallimard.

MoNTESINOS, José F. (1937): «Muerte y vida de Unamuno». En: Hora de España 4 (abril 1937), 11-21.

PaZ, Octavio (1990): Pequeña crónica de grandes días. México: Fondo de Cultura Económica.

—, (1993): Itinerario. México: Fondo de Cultura Económica.

SERRANO Plaja, Arturo (1937a): «A diestra y siniestra (los intelectuales y la guerra)». En: Hora de España 7 (julio 1937), 27-42.

-, (1937b): «Ponencia Colectiva, leída por Arturo Serrano Plaja». En: Hora de España 8 (agosto 1937), 83-95.

-, (1978): El hombre y el trabajo (1938). Introducción y notas de Francisco Caudet. Madrid: Ediciones de la Torre.

—, y Bergamín, José (1935): «El clavo ardiendo». En: Cruz y Raya 31 (noviembre 1935), 3-33.

SCHMITT, Hans Jürgen; SCHRAMM, Godehard (1974): Sozialistische Realismuskonzeptionen. Dokumente zum I. Allunionskongreß der Sowjetschriftsteller. Frankfurt: Suhrkamp.

Souchy, Augustin (1977): «Vorsicht Anarchist!» Ein Leben für die Freiheit. Politische Erinnerungen. Darmstadt-Neuwied: Luchterhand.

UnAmuno, Miguel de (1972): «La dignidad humana» (1896). En: Obras completas, I: Paisajes y Ensayos. Madrid: Escelicer, 971-977.

B. Estudios

AZNAR SOlER, Manuel (1987a): I Congreso Internacional de Escritores para la Defensa de la Cultura (París, 1935), 2 vols. Valencia: Generalitat Valenciana, Conselleria de Cultura, Educació y Ciència.

-, (1987b): II Congreso Internacional de Escritores para la Defensa de la Cultura (Valencia-Madrid-Barcelona-París, 1937), vol. II: Literatura española y antifascismo 
(1927-1939). Valencia: Generalitat Valenciana, Conselleria de Cultura, Educació y Ciència.

BERNECKER, Walter L. (1978): Anarchismus und Bürgerkrieg. Zur Geschichte der Sozialen Revolution in Spanien 1936-1939. Hamburg: Hoffmann und Campe.

Bolloten, Burnett (1991): The Spanish Civil War. Revolution and Counterrevolution. New York: Harvester Wheatsheaf.

CANO BALlESTA, Juan (1972): La poesía española entre pureza y revolución (1930-1936). Madrid: Gredos.

CAUdeT, Francisco (Selección y Prólogo) (1975a): Hora de España. Antología. Madrid: Ediciones Turner.

—, (1975b): «Visita al poeta Arturo Serrano Plaja». En: Camp de l'Arpa 16 (enero 1975), $15-18$.

—, (1984): «Arturo Serrano Plaja: Apostillas a algunos de sus ensayos». En: Aranguren, José Luis L.; Sánchez-Barbudo, Antonio (eds.): Homenaje a Arturo Serrano Plaja. Madrid: Taurus, 69-98.

DIESTE, Rafael (1983): Testimonios y Homenajes (Edición, prólogo y notas de Manuel Aznar Soler). Barcelona: Editorial Laia.

GöRling, Reinhold (1986): «Dinamita cerebral». Politischer Prozeß und ästhetische Praxis im Spanischen Bürgerkrieg (1936-1939). Frankfurt: Vervuert.

IBARRA, Jana (2000): 'Poesía pura' und 'poesía sin pureza' in Nerudas 'Caballo verde para la poesía'. Hamburg: Wissenschaftliche Hausarbeit zur Erlangung des akademischen Grades eines Magister Artium der Universität.

JACKSON, Gabriel (1999): La República Española y la Guerra Civil. Barcelona: Crítica.

MONTERO, Enrique (1977): «Octubre: revelación de una revista mítica». En: Octubre. Escritores y artistas revolucionarios. Reimpresión anastática de la edición de Madrid 1933-34. Vaduz/Liechtenstein: Topos Verlag, ix-xxxvi.

PÉREZ-RAMOS, Barbara (1990): «Poesía marginada en la Guerra Civil». En: Engelbert, Manfred; García de María, Javier (eds.): La Guerra Civil Española - medio siglo después. Frankfurt: Vervuert 1990, 91-109.

Preston, Paul (1996): A Concise History of the Spanish Civil War. London: Fontana Press.

-, (1999): Las tres Españas del 36. Barcelona: Plaza Janés.

SCHNEIDER, Luis Mario (1987): II Congreso Internacional de Escritores para la Defensa de la Cultura (Valencia-Madrid-Barcelona-París, 1937), vol. I: Inteligencia y Guerra Civil Española. Valencia: Generalitat Valenciana, Conselleria de Cultura, Educació i Ciència.

TAVERA, Susanna (1992): SOLIDARIDAD OBRERA. El fer-se i desfer-se d'un diari anarco-sindicalista (1915-1939). Barcelona: Diputació de Barcelona.

THOMAs, Hugh (1979): The Spanish Civil War. London: Penguin Books.

TRAPIELlo, Andrés (1994): Las armas y las letras. Literatura y guerra civil (1936-1939). Barcelona: Editorial Planeta (=Espejo de España).

VIDAL, César (1996): Durruti. La furia libertaria. Ediciones Temas de Hoy, S.A. (=Biografías). 


\title{
RESUMEN
}

La Ponencia Colectiva (1937) de Arturo Serrano Plaja: una toma de posición literaria y política en la Guerra Civil, por Klaus Meyer-Minnemann, Ana Luengo, Daniela Pérez y Effinger.

La Ponencia Colectiva, escrita por Arturo Serrano Plaja en nombre de la juventud, no sólo fue una reflexión sobre el oficio del escritor en la sociedad, sino también una toma de posición en el momento histórico concreto de la Guerra Civil Española. Se leyó en el II Congreso Internacional de Escritores para la Defensa de la Cultura, inspirado y dirigido por organismos y compañeros de ruta del Partido Comunista. Los firmantes de la Ponencia Colectiva reclamaban «un arte por y para el hombre», lejos del arte puro y del arte de propaganda. Ponían al servicio del gobierno republicano ayudado por la U.R.S.S. tanto su trabajo intelectual como su esfuerzo como hombres jóvenes en la lucha, rechazando el revolucionarismo libertario. Asimismo manifestaban su autonomía intelelectual y política, pretensión que les unía al proyecto de la revista، Hora de España, en la cual la mayoría de ellos colaboraba asiduamente.

Palabras clave: Serrano; Plaja; Ponencia; Congreso.

\begin{abstract}
The Ponencia Colectiva, written by Arturo Serrano Plaja in the name of the spanish youth, was not only a reflection on the writer's place in society, but also a statement in the concrete historical context of the Spanish Civil War. It was presented in the II Congreso Internacional de Escritores para la Defensa de la Cultura, which was inspired and directed by organisms and fellow travellers of the Communist Party. Those who signed the Ponencia Colectiva demanded an art centred in mankind, far away from the pure art and the propaganda art. They put at the disposal of the republican government, supported by the U.S.S.R., both their intellectual work and their effort as young men in the fight, rejecting the anarchic revolutionarism. They also declared their intellectual and political autonomy. This aspiration joined them to the project of the journal Hora de España, to which most of them were regular contributors.
\end{abstract}

Key words: Serrano; Plaja; Statement; Congress. 